\title{
Reduced opioid utilization and post-operative pain in Asian vs. Caucasian populations after video-assisted thoracoscopic surgery lobectomy with liposomal bupivacaine-based intercostal nerve blockade
}

\author{
Diana S. Hsu ${ }^{1,2} \wedge$, Sora Ely ${ }^{1,2}$, Nathan J. Alcasid ${ }^{1,2}$, Kian C. Banks ${ }^{1,2}$, Jesse Santos ${ }^{1,2}$, Julia Wei ${ }^{3}$, \\ Clara Maxim ${ }^{3}$, Simon K. Ashiku ${ }^{2}$, Ashish R. Patel ${ }^{2}$, Jeffrey B. Velotta ${ }^{2}$ \\ ${ }^{1}$ UCSF East Bay Surgery, Highland Hospital, Oakland, CA, USA; ${ }^{2}$ Thoracic Surgery Division, Department of Surgery, Kaiser Permanente Oakland \\ Medical Center, Oakland, CA, USA; ${ }^{3}$ Division of Research, Kaiser Permanente Northern California, Oakland, CA, USA \\ Contributions: (I) Conception and design: S Ely, JB Velotta; (II) Administrative support: S Ely, J Wei, JB Velotta; (III) Provision of study materials or \\ patients: All authors; (IV) Collection and assembly of data: All authors; (V) Data analysis and interpretation: All authors; (VI) Manuscript writing: All \\ authors; (VII) Final approval of manuscript: All authors. \\ Correspondence to: Diana S. Hsu, MD. UCSF East Bay Surgery, Highland Hospital, Oakland, CA 94602, USA. \\ Email: dianahsu@alamedahealthsystem.org.
}

Backgroundk Regional analgesia, such as intercostal nerve blockade (INB), is a viable modality for postoperative pain control in thoracic surgery patients. Asian patients have historically been underrepresented in studies of pain responses and pain medication requirements based on race. In this study, we examined the postoperative opioid medications used by Asian and Caucasian patients undergoing videoassisted thoracoscopic surgery (VATS) lobectomy who received different bupivacaine-based INB.

Mothods: We retrospectively reviewed patients undergoing VATS lobectomy who received standard bupivacaine (SB), liposomal bupivacaine (LB), or liposomal bupivacaine mixed with standard bupivacaine (MIX). Length of stay (LOS), postoperative pain scores, postoperative opioid use (in intravenous morphine equivalents) were evaluated. The Chi-square test was used to compare categorical variables; Student's $t$-test for normally distributed variables; and the Wilcoxon rank-sum test for non-normally distributed variables. Multivariable linear regression was used to assess opioid use in Asians compared to Caucasians.

Results: Of the 239 patients in the cohort, 212 received LB or MIX and 27 received SB. In the LB/MIX group, 48 (22.6\%) were Asian and 164 (77.4\%) were Caucasian. In the SB group, 7 (25.9\%) were Asian and 20 (74.1\%) were Caucasian. There were no differences in height, weight, and body mass index (BMI) between the SB and LB/MIX groups, but there was a significant difference in weight and BMI between Asian and Caucasian patients. The median LOS was comparable between the SB and LB/MIX groups. The average 24-hour postoperative pain score in the LB/MIX group was 2.5, and 2.0 and 2.7 in the Asian and Caucasian subgroups, respectively $(\mathrm{P}<0.01)$. The median opioid use in the LB/MIX group was $27.2 \mathrm{mg}$, and 16.9 and $31.1 \mathrm{mg}$ in the Asian and Caucasian subgroups, respectively $(\mathrm{P}<0.01)$. On multivariable linear regression analysis adjusting for sex, age, BMI, and bupivacaine type, we found Asians used $25.5 \mathrm{mg}$ less opioids compared to Caucasians $(\mathrm{P}<0.01)$.

Conclusions: INB with LB or liposomal-standard bupivacaine mix resulted in statistically significant decreased postoperative pain scores and opioid use in Asians compared to Caucasians. There was no difference in LOS between the LB/MIX and SB groups.

^ ORCID: 0000-0002-8215-856X. 
Keywords! Intercostal nerve blockade (INB); liposomal bupivacaine (LB); postoperative pain; opioid use; Asian

Submitted Aug 15, 2021. Accepted for publication Dec 03, 2021.

doi: 10.21037/apm-21-2269

View this article at: https://dx.doi.org/10.21037/apm-21-2269

\section{Introduction}

Thoracic surgery has traditionally utilized thoracic epidural analgesia (TEA) as the gold standard for postoperative pain control. However, in recent years, intercostal nerve blockade (INB) with standard bupivacaine (SB) or liposomal bupivacaine (LB) has been shown to be at least equivalent to TEA (1). There is some evidence that length of stay (LOS), pain scores, and postoperative opioid use are positively influenced by INB with either SB or LB (2-4). Our previous study demonstrated the benefits of INB whereby LB reduced LOS when compared to SB in a representative population.

Individual, organizational, and social factors contribute to individual differences in pain (5-13). Literature comparing Asians to other races identified that Asians have a lower pain threshold with enhanced sensitivity, different endogenous pain regulatory mechanisms, and higher pain ratings $(11,14,15)$.

In this cross-sectional study, we sought to demonstrate that for patients undergoing video-assisted thoracoscopic surgery (VATS) lobectomy, LB INB is associated with greater reduction in postoperative opioid utilization and pain scores among Asian patients than among Caucasian patients. We present the following article in accordance with the STROBE reporting checklist (available at https://apm. amegroups.com/article/view/10.21037/apm-21-2269/rc).

\section{Methods}

\section{Study design and population}

Patients who underwent VATS lobectomy from January 1, 2014 through July 31, 2018 were identified. Eligible patients were at least 18 years of age. Patient race was determined by patient's self-identification in the electronic health record. Patients were excluded from our analysis if they underwent a different type of surgery, their surgery was performed by a visiting surgeon, or they required an admission to the intensive care unit (ICU) following surgery. The rationale for the latter exclusion was that in our practice, fewer than $2 \%$ of patients go to the ICU, thus representing an exceptional circumstance, and the ICU care would likely preclude study of the outcome variables.

The study was approved by Kaiser Permanente Northern California IRB (No. CN-15-2502-H_06) and individual consent for this retrospective analysis was waived. The study was conducted in accordance with the Declaration of Helsinki (as revised in 2013).

\section{Analgesia formulations}

In our institutional practice, almost all thoracic surgery patients receive INB. A small proportion of cases receive TEA, after open cases; none receive TEA after VATS procedures. We studied all patients undergoing VATS lobectomy, grouped by three types of local anesthetic agent utilized in the INB: SB, LB, or liposomal bupivacaine mixed with standard bupivacaine (MIX). Our practice shifted uniformly over time from using SB to LB and finally to MIX INBs, so we retrospectively reviewed these temporal cohorts. We grouped LB and MIX into one cohort due to the small number of patients who received LB only.

In the $\mathrm{SB}$ group, $30 \mathrm{~mL}$ of $0.25 \% \mathrm{SB}$ with epinephrine $(1: 100,000)$ was injected. In the LB group, $266 \mathrm{mg}(20 \mathrm{~mL}$ diluted with normal saline to total volume of $30 \mathrm{~mL}$ ) was injected. In the MIX group, the same amount of the LB was mixed with $10 \mathrm{~mL}$ of the same SB with epinephrine solution as in the SB group, for a total of $30 \mathrm{~mL}$ of mixed solution.

Postoperatively, every patient is ordered acetaminophen $1,000 \mathrm{mg}$ every 6 hours, ibuprofen $600 \mathrm{mg}$ every 8 hours, a lidocaine patch, and gabapentin $300 \mathrm{mg}$ at bedtime. Patients with chronic kidney disease are not ordered ibuprofen and are ordered a lower dose of gabapentin. Oral and intravenous opioids are ordered in addition to nonopioid pain medications and administered to patients on an as needed basis by the nurses based on their subjective pain levels. Patients are not prescribed a patient-controlled analgesia (PCA) pump.

\section{Technique}

INB was performed percutaneously at the end of each operation under thoracoscopic visualization, prior to chest 
Table 1 Patient demographics and clinical characteristics by race

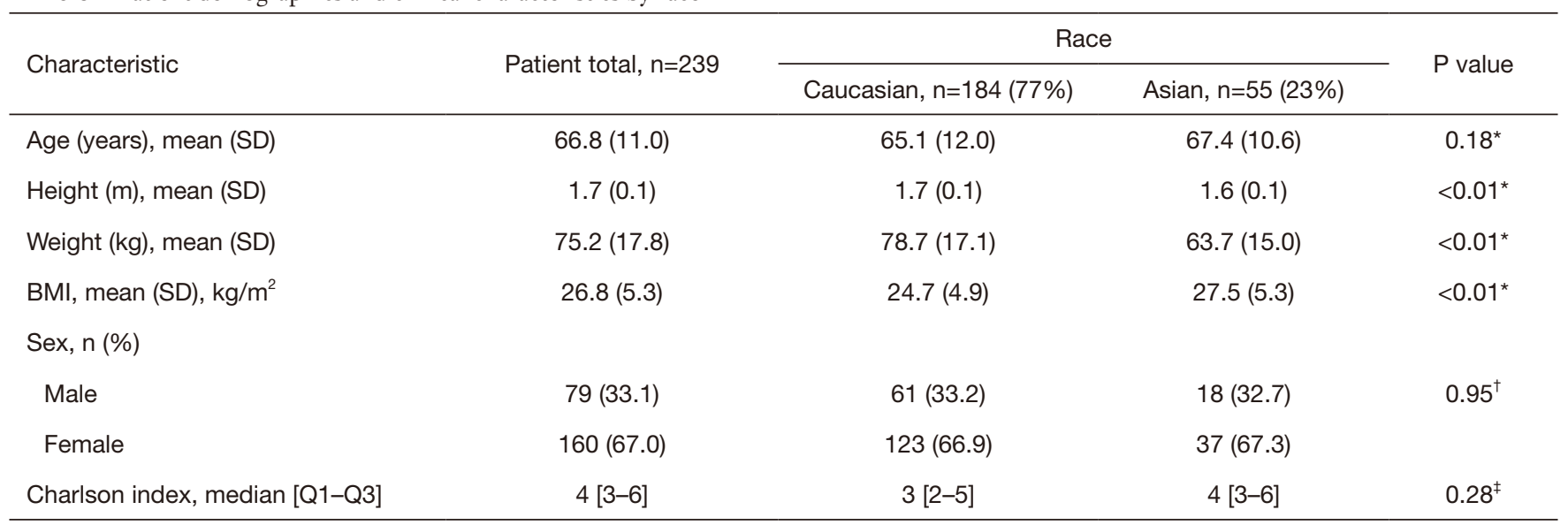

*, P value for comparison calculated by Student $t$-test; ${ }^{\dagger}, \mathrm{P}$ value for comparison calculated by Chi-square test; ${ }^{\ddagger}, \mathrm{P}$ value for comparison calculated by Wilcoxon rank-sum test. SD, standard deviation; BMI, body mass index.

tube placement. Local anesthetic was injected in equal amounts in each sequential rib space from one above through one below the most superior and inferior port sites. For our hospital system and surgeon group, this was decided to be the preferred nerve blockade method instead of the paravertebral approach. VATS lobectomies were performed via a three-port approach with minimal variability by one of the three board-certified thoracic surgeons who worked full-time at our facility during the specified time period.

\section{Data collection}

All data collected for analysis were extracted from the electronic medical record, either electronically by study programmers or by surgeon chart review. LOS was calculated by subtracting the date and time of hospital admission from the date and time of hospital discharge. Pain scores and ambulation data are routinely and reliably documented at our institution. Opioid administration was also gathered from the medical administration record and was quantified as morphine equivalents [oral, intravenous (IV), and total].

\section{Statistical analysis}

The primary outcome was LOS. Secondary outcomes were postoperative opioid medication usage (in morphine equivalents) and 24-hour postoperative pain scores. Frequencies, percentages, means and standard deviations, and medians and interquartile ranges were used to describe the variables. Chi-square tests were used to compare categorical variables, Student's $t$-test to compare normally distributed continuous variables, and Wilcox rank-sum tests to compare non-normally distributed continuous variables. Multivariable linear regression was performed to assess opioid use and LOS in Asians compared to Caucasians (reference), adjusting for age, gender, body mass index (BMI), and analgesia type. All data management and analyses were performed using Statistical Analysis Systems (SAS) 9.4 (Cary, NC, USA) with threshold for statistical significance defined as $\mathrm{P}<0.05$.

\section{Results}

\section{Cobort demographics and clinical characteristics}

The total cohort of 239 included 184 (77\%) Caucasian patients and 55 (23\%) Asian patients. Two thirds of the total cohort were female. Asian patients had a mean weight that was $15 \mathrm{~kg}$ lighter than the Caucasian patients $(\mathrm{P}<0.01)$ and a BMI that was almost $3 \mathrm{~kg} / \mathrm{m}^{2}$ higher than the Caucasian patients $(\mathrm{P}<0.01)$ (Table 1).

The number of patients who received LB or MIX in the study was 212; 48 (22.6\%) were Asian and 164 (77.4\%) were Caucasian. The number of patients who received SB was 27, of which 7 (25.9\%) were Asian and 20 (74.1\%) were Caucasian. There were no significant differences in patient characteristics between the SB and LB/MIX groups (Tables 2,3).

\section{Primary outcome}

The median LOS was 1.5 days for patients who received 
Table 2 Demographic and clinical characteristics by bupivacaine type

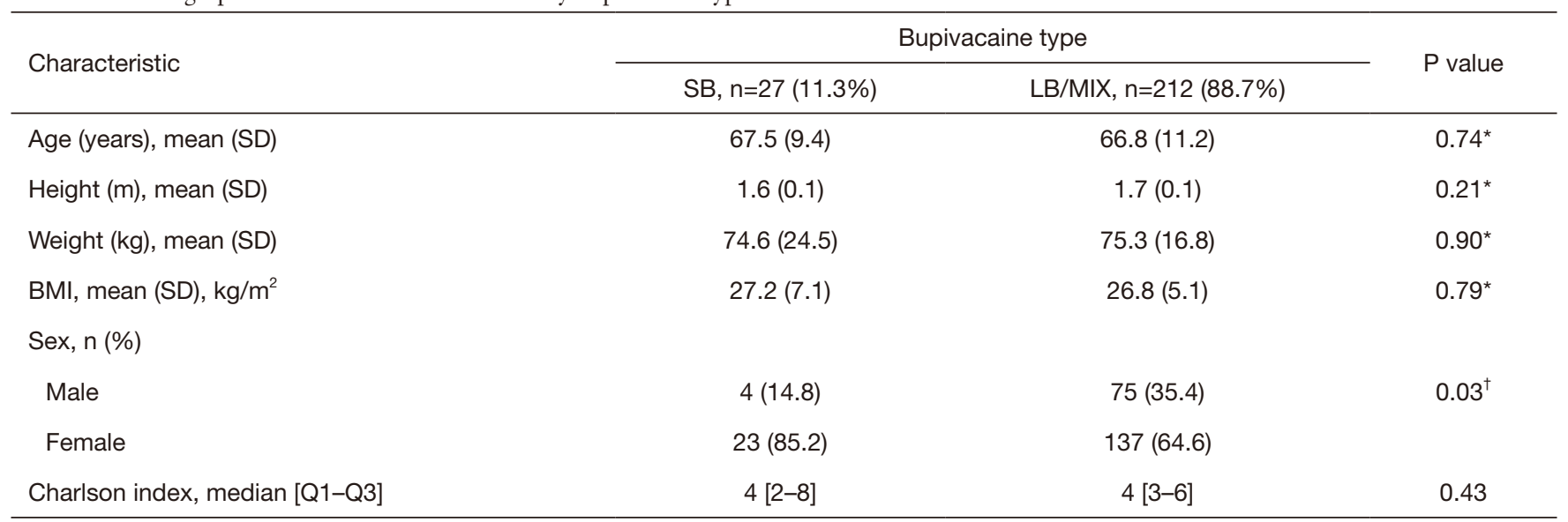

*, P value for comparison calculated by Student $t$-test; ${ }^{\dagger}, \mathrm{P}$ value for comparison calculated by Chi-square test. SB, standard bupivacaine; LB/MIX, liposomal bupivacaine and liposomal-standard mix bupivacaine; SD, standard deviation; BMI, body mass index.

LB/MIX and 2.4 days for SB, but this was not statistically significant (Table 3). Subgroup analysis of LOS in patients who received SB and LB/MIX demonstrated no statistically significant difference between Asians and Caucasians.

\section{Secondary outcomes}

In the LB/MIX group, the average 24-hour postoperative pain score was 2.5 and differed significantly between the Asian and Caucasian subgroups (2.0 vs. 2.7, respectively; $\mathrm{P}<0.01)$. Median opioid use, in intravenous morphine equivalents, was $27.2 \mathrm{mg}$ and also differed significantly between Asian patients and Caucasian patients, with the former having a median use of $10 \mathrm{mg}$ less than the overall median, $16.9 \mathrm{mg}$, whereas the latter had a median use of $14 \mathrm{mg}$ higher than the median, $31.1 \mathrm{mg}(\mathrm{P}<0.01)$.

In the SB group, the average 24-hour postoperative pain score was 2.4 and did not differ significantly between the Asian and Caucasian subgroups (1.9 vs. 2.6; $\mathrm{P}=0.31$ ). Median opioid use was $27.8 \mathrm{mg}$ for the group and did not differ significantly between the Asian and Caucasian subgroups (24.3 vs. $29.0 \mathrm{mg} ; \mathrm{P}=0.76$ ) (Table 3).

Multivariable linear regression analysis showed that Asians used $25.5 \mathrm{mg}$ less opioids than Caucasians after adjusting for sex, age, weight, BMI, and bupivacaine type $(\mathrm{P}<0.01)$ (Table 4). Age was another statistically significant factor in opioid use. For every 10 -year increase in age, there was a $10-\mathrm{mg}$ decrease in opioids used $(\mathrm{P}<0.01)$.

A second multivariable linear regression analysis comparing LOS between Asian and Caucasian patients showed that age was again a significant factor and for every 10 year-increase in age, there was almost a one day increase in LOS $(\mathrm{P}<0.01)$ (Table 5). Weight, BMI, and LB were not significant factors.

An adjusted means analysis of postoperative outcomes was done because of the smaller number of Asian patients and patients who received SB in this study (Table 6). Differences in LOS were not significant when analyzed by race and type of bupivacaine received. Although difference in postoperative opioid use was not statistically significant between SB and LB/MIX patients overall $(\mathrm{P}=0.48)$, the difference between Asian and Caucasian patients was. The adjusted mean opioid use in Asian patients was $25 \mathrm{mg}$ less than that in Caucasian patients $(\mathrm{P}<0.01)$.

\section{Discussion}

Asian patients have historically been underrepresented in studies of pain response and pain medication requirements based on race. In this study, we sought to demonstrate that for patients undergoing VATS lobectomy, LB INB is associated with greater reduction in postoperative opioid use and pain scores in Asian patients as compared to Caucasian patients. Our results show that the primary outcome of median LOS did not differ significantly between these two groups, either for those who received SB or those who received LB/MIX. The secondary outcomes of 24-hour postoperative pain score and median opioid use did differ between the Asian and Caucasian subgroups who received LB/MIX, but not for those who received SB. 
Table 3 Patient post-operative outcomes

\begin{tabular}{|c|c|c|c|c|c|c|c|c|c|}
\hline Post-operative outcome & $\begin{array}{c}\text { Patient } \\
\text { total, } n=239\end{array}$ & \multicolumn{4}{|c|}{ SB } & \multicolumn{4}{|c|}{ LB/MIX } \\
\hline $\begin{array}{l}\text { Average } 24 \text {-hour post-operative } \\
\text { pain score, mean (SD) }\end{array}$ & $2.5(1.2)$ & $2.4(1.4)$ & $1.9(0.9)$ & $2.6(1.6)$ & $0.31^{*}$ & $2.5(1.2)$ & $2.0(1.0)$ & $2.7(1.2)$ & $<0.01^{*}$ \\
\hline $\begin{array}{l}\text { Opioid use (IV morphine } \\
\text { equivalents, mg), median (Q1-Q3) }\end{array}$ & $\begin{array}{c}27.3 \\
(15.9-41.1)\end{array}$ & $\begin{array}{c}27.8 \\
(12.7-51.8)\end{array}$ & $\begin{array}{c}24.3 \\
(16.1-34.8)\end{array}$ & $\begin{array}{c}29.0 \\
(12.3-58.4)\end{array}$ & $0.76^{\dagger}$ & $\begin{array}{c}27.2 \\
(16.0-40.9)\end{array}$ & $\begin{array}{c}16.9 \\
(10.0-27.5)\end{array}$ & $\begin{array}{c}31.1 \\
(19.7-47.7)\end{array}$ & $<0.01^{\dagger}$ \\
\hline Length of stay (days), mean (SD) & $2.5(5.6)$ & $2.6(1.2)$ & $2.6(1.3)$ & $2.6(1.2)$ & $0.94^{*}$ & $2.5(5.9)$ & $1.5(1.3-2.3)$ & $2.1(1.2)$ & $0.30^{*}$ \\
\hline $\begin{array}{l}\text { Length of stay (days), median } \\
\text { (Q1-Q3) }\end{array}$ & $\begin{array}{c}1.5 \\
(1.3-2.4)\end{array}$ & $2.4(1.5-3.5)$ & $\begin{array}{c}3.3 \\
(1.3-3.5)\end{array}$ & $2.4(1.5-3.6)$ & $0.70^{\dagger}$ & $1.5(1.3-2.4)$ & $1.5(1.3-2.3)$ & $1.4(1.3-2.4)$ & $0.66^{\dagger}$ \\
\hline
\end{tabular}

${ }^{*}$, P value for comparison calculated by Student $t$-test; ${ }^{\dagger}, \mathrm{P}$ value for comparison calculated by Wilcoxon rank-sum test. SB, standard bupivacaine; LB/MIX, liposomal bupivacaine and liposomal-standard mix bupivacaine; SD, standard deviation; IV, intravenous.

Although the median LOS in the LB/MIX group was one day shorter than in the SB group, this difference was not statistically significant (Figure 1). This may have been due to the small sample size $(\mathrm{n}=27)$ in the SB group. Our previous study of patients undergoing VATS identified a significant difference in LOS for patients who received LB $v s$. SB, but we did not analyze differences based on race (16). However, despite the difference of LOS not reaching statistical significance, the trend in LOS in this study is similar to the 1-day shorter LOS we identified in the LB group previously (16). This can be further researched with a larger cohort.

The discussion around pain response, experience, and management based on race is multifaceted. A recent study by Rivas et al. (17) reported that Asians who received LB for a variety of surgeries had a statistically significant, though small, decrease in pain score, and did not have a higher opioid consumption compared to Caucasians. Our study identified a similar decrease in pain score between Asian and Caucasian patients but in contrast found a significant decrease in postoperative opioid pain medication use. Kodia et al. (18) found that using LB instead of bupivacaine/ epinephrine resulted in lower total in-hospital opioid use and lower pain scores on postoperative day 2 and 3, and no difference in LOS. Both the opioid use and LOS findings are similar to our findings, but since Kodia et al. (18) did not analyze opioid usage by race, no comparison is possible. Our study showed that when they received LB/MIX, Asians reported a median pain score of 0.7 less than Caucasians and used a significantly smaller amount (16.9 vs. $31.1 \mathrm{mg}$ ) of opioid medication than Caucasian patients. However, for those who received SB, this difference in opioid medication use between Asian and Caucasian patients was not statistically significant. This could be due to a small sample size and underpowering in this group or could demonstrate that there is no racial difference in postoperative opioid medication use when patients receive SB. If there is no difference in postoperative opioid medication use in the SB group, this could imply that Asian patients have better pain control than Caucasian patients specifically when LB is used.

According to our linear regression analyses, regardless of the type of INB the patients received, Asian patients used less opioid medication than Caucasian patients. There are several possible explanations for this, such as using positive thinking and exercise as an effective pain coping mechanism, reticence regarding requesting pain medications, presence of language barriers, and differences in nursing assessment $(12,19,20)$. Another theory as to why Asian patients received less opioid medication is that Asian patients in our study were on average $15 \mathrm{~kg}$ lighter than Caucasian patients and that this may affect both the amount of opioid and INB required. Although Asian patients weighed less on average than Caucasian patients, Asian patients had a mean BMI that was $3 \mathrm{~kg} / \mathrm{m}^{2}$ higher than Caucasian patients $(27.5 \mathrm{vs}$. $24.7 \mathrm{~kg} / \mathrm{m}^{2}$, respectively). In a study of opioid use after pediatric spinal surgery, the high-use group had a higher BMI $\left(23.7 v s .19 .6 \mathrm{~kg} / \mathrm{m}^{2} ; \mathrm{P}=0.04\right)$ and mean weight $(69.5 v s$. $50.7 \mathrm{~kg} ; \mathrm{P}=0.004)(20)$. The authors concluded that opioid 
Table 4 Multivariable linear regression comparison of Asians to Caucasians (reference) for opioid use

\begin{tabular}{lcc}
\hline Parameter & $\beta(95 \% \mathrm{Cl})$ & $\mathrm{P}$ value \\
\hline Intercept & $116.0(76.0,156.1)$ & $<0.01$ \\
Asian (ref = Caucasian) & $-25.5(-38.9,-12.1)$ & $<0.01$ \\
Male (ref = female) & $12.3(-2.3,26.8)$ & 0.10 \\
Age (10-year units) & $-10.7(-15.3,-6.1)$ & $<0.01$ \\
LB (ref = standard-release) & $-5.7(-21.2,9.9)$ & 0.47 \\
BMI, kg/m ${ }^{2}$ & $1.6(-0.8,3.9)$ & 0.19 \\
CCl score & $-1.2(-3.4,0.9)$ & 0.25 \\
Weight (10 kg units) & $-5.1(-13.1,3.0)$ & 0.22 \\
\hline
\end{tabular}

$\mathrm{Cl}$, confidence interval; LB, liposomal bupivacaine; BMI, body mass index; $\mathrm{CCl}$, Charlson comorbidity index.

Table 5 Multivariable linear regression comparison of Asians to Caucasians (reference) for LOS

\begin{tabular}{lcc}
\hline Parameter & $\beta(95 \% \mathrm{Cl})$ & $\mathrm{P}$ value \\
\hline Intercept & $-2.2(-7.8,3.4)$ & 0.44 \\
Asian (ref = Caucasian) & $0.9(-0.9,2.8)$ & 0.33 \\
Male (ref = female) & $2.7(0.7,4.8)$ & 0.01 \\
Age (10-year units) & $0.9(0.3,1.6)$ & $<0.01$ \\
LB (ref = standard-release) & $-0.4(-2.6,1.7)$ & 0.69 \\
BMl, kg/m & $0.2(-0.1,0.5)$ & 0.27 \\
CCl score & $0.0(-0.3,0.3)$ & 0.78 \\
Weight (10 kg units) & $-1.0(-2.1,0.1)$ & 0.09 \\
\hline
\end{tabular}

LOS, length of stay; Cl, confidence interval; LB, liposomal bupivacaine; BMI, body mass index; CCI, Charlson comorbidity index.

Table 6 Adjusted means of post-operative outcomes

\begin{tabular}{lccccccc}
\hline \multirow{2}{*}{ Post-operative outcome } & \multicolumn{3}{c}{ Race/ethnicity } & & \multicolumn{3}{c}{ Bupivacaine type } \\
\cline { 2 - 3 } \cline { 6 - 8 } & Asian & White & P value & & SB & LB/MIX & P value \\
\hline Opioid use (IV morphine equivalents, mg) & 16.5 & 42.0 & $<0.01$ & & 41.3 & 35.6 & 0.48 \\
LOS (days) & 3.2 & 2.3 & 0.34 & 2.9 & 2.4 & 0.70 \\
\hline
\end{tabular}

Means adjusted for age, sex, BMI, weight, CCI score, and bupivacaine type. SB, standard bupivacaine; LB/MIX, liposomal bupivacaine and liposomal-standard mix bupivacaine; IV, intravenous; LOS, length of stay; BMI, body mass index; CCI, Charlson comorbidity index.

dosing may be improved by considering patient weight and other factors. In an emergency department study, weight was not a factor in response to morphine in opioid naïve adults (21). Another study of pain management with a fixed amount of hydromorphone found no correlation between total body weight and a patient's clinical response to hydromorphone and was unable to conclude that weight- based dosing is better than fixed dosing (22). Furthermore, dosing of medications including analgesics for obese patients is suggested to be based on ideal body weight or adjusted body weight (23). These studies have different conclusions about weight and BMI-dosing for opioid medications, likely because the effect of opioids is a complex aggregate of pharmacodynamics, genetics of metabolism, 


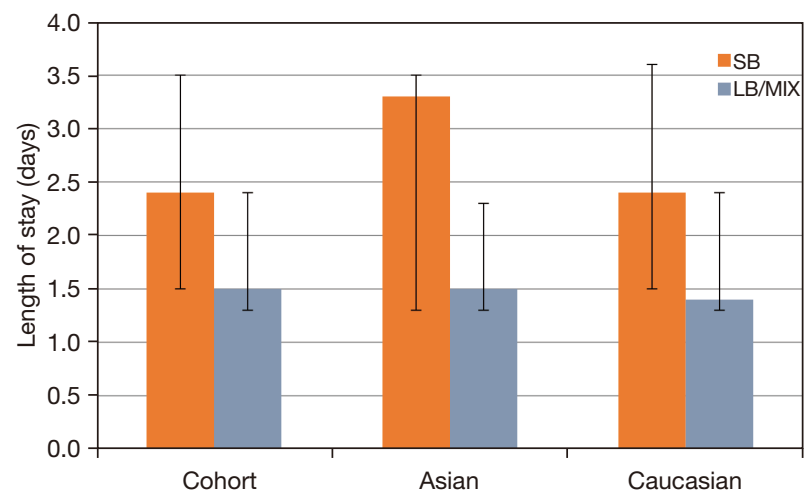

Figure 1 Median and interquartile ranges of LOS (days) by bupivacaine type. SB, standard bupivacaine; LB/MIX, liposomal bupivacaine and liposomal-standard mix bupivacaine; LOS, length of stay.

and history of opioid use. Similarly, our multivariable analysis did not identify weight and BMI as significant factors in determining amount of opioids used.

In LB studies, different anesthetic regimens are more frequently compared than the outcomes based on race and other patient factors such as weight $(24,25)$. Asian patients are underrepresented not only in studies of pain response and management, but also specifically involving thoracic surgery and regional analgesia, such as INB. Regional analgesia should be further investigated, and standardization of dosing improved (26). Even in pediatric medicine, where many medications are age- and weight-based, there is still uncertainty regarding dosing of regional analgesia $(27,28)$. Narcotic pain medication and regional analgesia dosing, whether adjusted by weight or metabolism, is an important avenue to explore to better tailor pain regimens.

The findings of decreased opioid use with increasing age was not the primary focus of this study. However, this finding is similar to those of other studies that identified lower postoperative pain scores and opioid use in older patients $(29,30)$.

Our study highlights the intriguing interplay of pharmacokinetic and pharmacodynamics regarding LB and opioid usage in Asian patients. Our findings of decreased pain scores and opioid usage in Asian vs. Caucasian patients should initiate better tailoring of postoperative pain regimens for thoracic surgery. Along those lines, a 2014 study of the combined effects of pharmacokinetics and pharmacogenetics included a design for personalized oxycodone dosing for chronic pain patients to limit iatrogenic overdose or death (31). In addition, studies in predominantly Asian countries, such as South Korea, identified similar benefits in LB over SB for postoperative thoracic pain management (32). Areas of future research include combining results from these studies to help standardize the approach to precision medicine for Asian patients undergoing thoracic surgery. Randomized controlled trials comparing metabolism of narcotics and local analgesia based on race and genetics are needed, specifically for thoracic surgery patients, with an emphasis on Asians, who have historically been underrepresented in studies of pain management.

Our study is limited by its retrospective nature, making the results susceptible to confounding by unidentified variables. Second, our cohort was predominantly female, which is not representative of gender statistics of lung cancer diagnoses in the United States (33). The predominantly female cohort could affect our results due to factors such as biochemical processes and differences in reactions and response to postoperative pain (34-36). Third, the self-identification of "Asian" and "Caucasian" are broad terms that do not take into account region of ancestry, place of birth, and other genetic and sociocultural factors that could potentially affect responses to pain or local and systemic analgesia. Lastly, although our previous study concluded an improvement in postoperative pain with the use of LB, this has not been uniformly identified in the literature. Hussain et al. identified no clinically significant difference in postoperative pain when between liposomal and nonliposomal bupivacaine is used for nerve blocks (37).

\section{Conclusions}

We identified decreased pain scores and significantly decreased opioid use in Asian patients who received LB INB compared to Caucasian patients. The same pattern was not found in patients who received SB, perhaps because of the small sample size. Future studies are needed to better characterize the differences in postoperative pain and analgesic needs among Asian patients undergoing thoracic surgery.

\section{Acknowledgments}

Funding: None. 


\section{Footnote}

Reporting Checklist: The authors have completed the STROBE reporting checklist. Available at https://apm. amegroups.com/article/view/10.21037/apm-21-2269/rc

Data Sharing Statement: Available at https://apm.amegroups. com/article/view/10.21037/apm-21-2269/dss

Peer Review File: Available at https://apm.amegroups.com/ article/view/10.21037/apm-21-2269/prf

Conflicts of Interest: All authors have completed the ICMJE uniform disclosure form (available at https://apm. amegroups.com/article/view/10.21037/apm-21-2269/coif). The authors have no conflicts of interest to declare.

Ethical Statement: The authors are accountable for all aspects of the work in ensuring that questions related to the accuracy or integrity of any part of the work are appropriately investigated and resolved. The study was approved by Kaiser Permanente Northern California IRB (No. CN-15-2502-H_06) and individual consent for this retrospective analysis was waived. The study was conducted in accordance with the Declaration of Helsinki (as revised in 2013).

Open Access Statement: This is an Open Access article distributed in accordance with the Creative Commons Attribution-NonCommercial-NoDerivs 4.0 International License (CC BY-NC-ND 4.0), which permits the noncommercial replication and distribution of the article with the strict proviso that no changes or edits are made and the original work is properly cited (including links to both the formal publication through the relevant DOI and the license). See: https://creativecommons.org/licenses/by-nc-nd/4.0/.

\section{References}

1. Haager B, Schmid D, Eschbach J, et al. Regional versus systemic analgesia in video-assisted thoracoscopic lobectomy: a retrospective analysis. BMC Anesthesiol 2019;19:183.

2. Khalil KG, Boutrous ML, Irani AD, et al. Operative Intercostal Nerve Blocks With Long-Acting Bupivacaine Liposome for Pain Control After Thoracotomy. Ann Thorac Surg 2015;100:2013-8.

3. Rice DC, Cata JP, Mena GE, et al. Posterior Intercostal
Nerve Block With Liposomal Bupivacaine: An Alternative to Thoracic Epidural Analgesia. Ann Thorac Surg 2015;99:1953-60.

4. Tomov M, Tou K, Winkel R, et al. Does Subcutaneous Infiltration of Liposomal Bupivacaine Following SingleLevel Transforaminal Lumbar Interbody Fusion Surgery Improve Immediate Postoperative Pain Control? Asian Spine J 2018;12:85-93.

5. Cepeda MS, Farrar JT, Roa JH, et al. Ethnicity influences morphine pharmacokinetics and pharmacodynamics. Clin Pharmacol Ther 2001;70:351-61.

6. Lee A, Gin T, Oh TE. Opioid requirements and responses in Asians. Anaesth Intensive Care 1997;25:665-70.

7. Ortolani O, Conti A, Ngumi ZW, et al. Ethnic differences in propofol and fentanyl response: a comparison among Caucasians, Kenyan Africans and Brazilians. Eur J Anaesthesiol 2004;21:314-9.

8. Tan EC, Lim Y, Teo YY, et al. Ethnic differences in pain perception and patient-controlled analgesia usage for postoperative pain. J Pain 2008;9:849-55.

9. Campbell CM, Edwards RR. Ethnic differences in pain and pain management. Pain Manag 2012;2:219-30.

10. Campbell CM, Edwards RR, Fillingim RB. Ethnic differences in responses to multiple experimental pain stimuli. Pain 2005;113:20-6.

11. Kim HJ, Yang GS, Greenspan JD, et al. Racial and ethnic differences in experimental pain sensitivity: systematic review and meta-analysis. Pain 2017;158:194-211.

12. Meints SM, Cortes A, Morais CA, et al. Racial and ethnic differences in the experience and treatment of noncancer pain. Pain Manag 2019;9:317-34.

13. Ahn H, Weaver M, Lyon DE, et al. Differences in Clinical Pain and Experimental Pain Sensitivity Between Asian Americans and Whites With Knee Osteoarthritis. Clin J Pain 2017;33:174-80.

14. Rowell LN, Mechlin B, Ji E, et al. Asians differ from nonHispanic Whites in experimental pain sensitivity. Eur J Pain 2011;15:764-71.

15. Watson PJ, Latif RK, Rowbotham DJ. Ethnic differences in thermal pain responses: a comparison of South Asian and White British healthy males. Pain 2005;118:194-200.

16. Dominguez DA, Ely S, Bach C, et al. Impact of intercostal nerve blocks using liposomal versus standard bupivacaine on length of stay in minimally invasive thoracic surgery patients. J Thorac Dis 2018;10:6873-9.

17. Rivas E, Cohen B, Adegboye J, et al. Ethnic Differences in Analgesic Efficacy and Safety of Liposomal Bupivacaine Among Asian and Caucasian Surgical Patients: A 
Retrospective Matched-Cohort Analysis. Asian J Anesthesiol 2020;58:99-110.

18. Kodia K, Razi SS, Stephens-McDonnough JA, et al. Liposomal Bupivacaine Versus Bupivacaine/Epinephrine Intercostal Nerve Block as Part of an Enhanced Recovery After Thoracic Surgery (ERATS) Care Pathway for Robotic Thoracic Surgery. J Cardiothorac Vasc Anesth 2021;35:2283-93.

19. Houghton IT, Aun CS, Gin T, et al. Inter-ethnic differences in postoperative pethidine requirements. Anaesth Intensive Care 1992;20:52-5.

20. Johnson JD, Asiodu IV, McKenzie CP, et al. Racial and Ethnic Inequities in Postpartum Pain Evaluation and Management. Obstet Gynecol 2019;134:1155-62.

21. Grant DR, Schoenleber SJ, McCarthy AM, et al. Are We Prescribing Our Patients Too Much Pain Medication? Best Predictors of Narcotic Usage After Spinal Surgery for Scoliosis. J Bone Joint Surg Am 2016;98:1555-62.

22. Patanwala AE, Edwards CJ, Stolz L, et al. Should morphine dosing be weight based for analgesia in the emergency department? J Opioid Manag 2012;8:51-5.

23. Erstad BL, Barletta JF. Drug dosing in the critically ill obese patient-a focus on sedation, analgesia, and delirium. Crit Care 2020;24:315.

24. Xia S, Choe D, Hernandez L, et al. Does initial hydromorphone relieve pain best if dosing is fixed or weight based? Ann Emerg Med 2014;63:692-8.e4.

25. Meyer LA, Corzo C, Iniesta MD, et al. A prospective randomized trial comparing liposomal bupivacaine vs standard bupivacaine wound infiltration in open gynecologic surgery on an enhanced recovery pathway. Am J Obstet Gynecol 2021;224:70.e1-70.e11.

26. Springer BD, Mason JB, Odum SM. Systemic Safety of Liposomal Bupivacaine in Simultaneous Bilateral Total Knee Arthroplasty. J Arthroplasty 2018;33:97-101.

27. Yelnik AP, Hentzen C, Cuvillon P, et al. French clinical guidelines for peripheral motor nerve blocks in a PRM

Cite this article as: Hsu DS, Ely S, Alcasid NJ, Banks KC, Santos J, Wei J, Maxim C, Ashiku SK, Patel AR, Velotta JB. Reduced opioid utilization and post-operative pain in Asian vs. Caucasian populations after video-assisted thoracoscopic surgery lobectomy with liposomal bupivacaine-based intercostal nerve blockade. Ann Palliat Med 2022;11(5):1635-1643. doi: 10.21037/apm-21-2269 setting. Ann Phys Rehabil Med 2019;62:252-64.

28. Suresh S, Ecoffey C, Bosenberg A, et al. The European Society of Regional Anaesthesia and Pain Therapy/ American Society of Regional Anesthesia and Pain Medicine Recommendations on Local Anesthetics and Adjuvants Dosage in Pediatric Regional Anesthesia. Reg Anesth Pain Med 2018;43:211-6.

29. Tighe PJ, Le-Wendling LT, Patel A, et al. Clinically derived early postoperative pain trajectories differ by age, sex, and type of surgery. Pain 2015;156:609-17.

30. Sun K, Liu D, Chen J, et al. Moderate-severe postoperative pain in patients undergoing video-assisted thoracoscopic surgery: A retrospective study. Sci Rep 2020;10:795.

31. Linares OA, Daly D, Linares AD, et al. Personalized oxycodone dosing: using pharmacogenetic testing and clinical pharmacokinetics to reduce toxicity risk and increase effectiveness. Pain Med 2014;15:791-806.

32. Kim DH, Oh YJ, Lee JG, et al. Efficacy of UltrasoundGuided Serratus Plane Block on Postoperative Quality of Recovery and Analgesia After Video-Assisted Thoracic Surgery: A Randomized, Triple-Blind, Placebo-Controlled Study. Anesth Analg 2018;126:1353-61.

33. SEER. Available online: https://seer.cancer.gov/statfacts/ html/lungb.html

34. Greenspan JD, Craft RM, LeResche L, et al. Studying sex and gender differences in pain and analgesia: a consensus report. Pain 2007;132 Suppl 1:S26-45.

35. Fillingim RB, King CD, Ribeiro-Dasilva MC, et al. Sex, gender, and pain: a review of recent clinical and experimental findings. J Pain 2009;10:447-85.

36. Casale R, Atzeni F, Bazzichi L, et al. Pain in Women: A Perspective Review on a Relevant Clinical Issue that Deserves Prioritization. Pain Ther 2021;10:287-314.

37. Hussain N, Brull R, Sheehy B, et al. Perineural Liposomal Bupivacaine Is Not Superior to Nonliposomal Bupivacaine for Peripheral Nerve Block Analgesia. Anesthesiology 2021;134:147-64. 